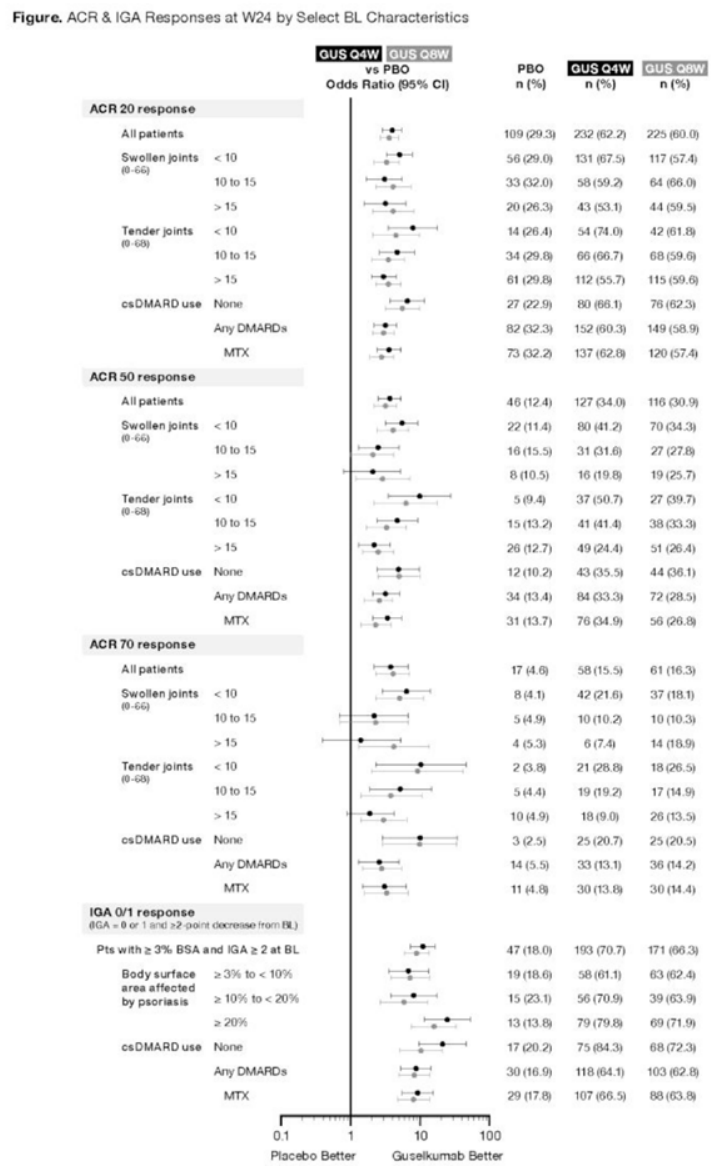

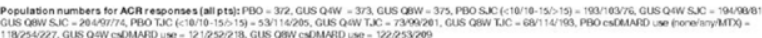

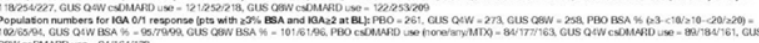

Figure 1

Table 1. ACR \& IGA Responses at Weeks $24 \& 52 \&$ by Select BL Characteristics

\begin{tabular}{|c|c|c|c|c|}
\hline & \multirow{2}{*}{\multicolumn{2}{|c|}{$\begin{array}{c}\text { Guselkumab Q4W } \\
\mathrm{N}=373\end{array}$}} & \multicolumn{2}{|c|}{ Guselkumab Q8W } \\
\hline & & & \multicolumn{2}{|c|}{$\mathrm{N}=375$} \\
\hline & Week 24 & Week 52 & Week 24 & Week 52 \\
\hline ACR20, \% & 62 & 72 & 60 & 70 \\
\hline $\operatorname{SJC}(<10 / 10-15 />15)$ & $68 / 59 / 53$ & $79 / 61 / 67$ & $57 / 66 / 60$ & $68 / 68 / 76$ \\
\hline $\operatorname{TJC}(<10 / 10-15 />15)$ & $74 / 67 / 56$ & $73 / 76 / 69$ & $62 / 60 / 60$ & $75 / 68 / 68$ \\
\hline csDMARD use (none/any/MTX) & $66 / 60 / 63$ & $80 / 68 / 68$ & $62 / 59 / 57$ & $73 / 68 / 68$ \\
\hline ACR50, \% & 34 & 49 & 31 & 45 \\
\hline SJC $(<10 / 10-15 />15)$ & $41 / 32 / 20$ & $58 / 39 / 38$ & $34 / 28 / 26$ & $46 / 40 / 49$ \\
\hline $\operatorname{TJC}(<10 / 10-15 />15)$ & $51 / 41 / 24$ & $58 / 53 / 43$ & $40 / 33 / 26$ & $52 / 46 / 43$ \\
\hline csDMARD use (none/any/MTX) & $36 / 33 / 35$ & $53 / 46 / 48$ & $36 / 29 / 27$ & $51 / 42 / 40$ \\
\hline ACR70, \% & 16 & 27 & 16 & 27 \\
\hline $\operatorname{SJC}(<10 / 10-15 />15)$ & $22 / 10 / 7$ & $32 / 20 / 24$ & $18 / 10 / 19$ & $30 / 23 / 26$ \\
\hline $\operatorname{TJC}(<10 / 10-15 />15)$ & 29/19/9 & $34 / 32 / 22$ & $27 / 15 / 14$ & $35 / 28 / 24$ \\
\hline \multirow[t]{2}{*}{ csDMARD use (none/any/MTX) } & $21 / 13 / 14$ & $30 / 26 / 27$ & $21 / 14 / 14$ & $34 / 24 / 23$ \\
\hline & \multicolumn{2}{|c|}{$\mathrm{N}=273$} & \multicolumn{2}{|c|}{$\mathrm{N}=\mathbf{2 5 8}$} \\
\hline IGA $0 / 1, \%$ & 71 & 80 & 66 & 71 \\
\hline BSA \% with psoriasis & $61 / 71 / 80$ & $76 / 87 / 79$ & $62 / 64 / 72$ & $67 / 72 / 74$ \\
\hline \multicolumn{5}{|l|}{$(\geq 3-<10 / \geq 10-<20 / \geq 20)$} \\
\hline csDMARD use (none/any/MTX) & $84 / 64 / 67$ & $87 / 77 / 78$ & $72 / 63 / 64$ & $77 / 68 / 68$ \\
\hline
\end{tabular}

Disclosure of Interests: Christopher T. Ritchlin Consultant of: AbbVie, Amgen, Gilead, Janssen, Eli Lilly, Novartis, Pfizer, and UCB Pharma, Grant/research support from: AbbVie, Amgen, and UCB Pharma, Philip J Mease Consultant of: AbbVie, Amgen, Boehringer Ingelheim, Bristol Myers Squibb, Eli Lilly, Galapagos, Gilead, GlaxoSmithKline, Janssen, Novartis, Pfizer, SUN, and UCB Pharma, Grant/ research support from: AbbVie, Amgen, Bristol Myers Squibb, Eli Lilly, Galapagos, Gilead, Janssen, Novartis, Pfizer, SUN, and UCB Pharma, Wolf-Henning Boehncke Speakers bureau: AbbVie, Almirall, Celgene, Janssen, Leo, Eli Lilly, Novartis, UCB Pharma, Consultant of: AbbVie, Almirall, Celgene, Janssen, Leo, Eli Lilly, Novartis,
UCB Pharma, Grant/research support from: Pfizer, John Tesser Speakers bureau: AbbVie, Amgen, AstraZeneca, Bristol Myers Squibb, Crescendo Biosciences/Myriad, GlaxoSmithKline, Genentech, Janssen, Eli Lilly, and Pfizer, Consultant of: AbbVie AstraZeneca, Bristol Myers Squibb, Gilead, Janssen, Eli Lilly, Novartis, and Pfizer Grant/research support from: AbbVie, Bristol Myers Squibb, Boehringer Ingelheim, Celgene, Horizon, Janssen, Eli Lilly, Merck KG, Novartis, Pfizer, Sandoz, Sun Pharma, Setpoint, and UCB Pharma, Elena Schiopu Consultant of: Janssen, Grant/ research support from: Janssen, Soumya D Chakravarty Shareholder of: Johnson \& Johnson, of which Janssen Research \& Development is a wholly owned subsidiary, Employee of: Janssen Scientific Affairs, LLC, Alexa Kollmeier Shareholder of: Johnson \& Johnson, of which Janssen Research \& Development is a wholly owned subsidiary, Employee of: Janssen Research \& Development, LLC, Elizabeth C Hsia Shareholder of: Johnson \& Johnson, of which Janssen Research \& Development is a wholly owned subsidiary, Employee of: Janssen Research \& Development LLC, Xie L Xu Shareholder of: Johnson \& Johnson, of which Janssen Research \& Development is a wholly owned subsidiary, Employee of: Janssen Research \& Development, LLC, May Shawi Shareholder of: Johnson \& Johnson, of which Janssen Research \& Development is a wholly owned subsidiary, Employee of: Janssen Global Services, LLC, Yusang Jiang Employee of: Cytel, Inc., providing statistical support (funded by Janssen), Shihong Sheng Shareholder of: Johnson \& Johnson, of which Janssen Research \& Development is a wholly owned subsidiary, Employee of: Janssen Research \& Development, LLC, Joseph F. Merola Consultant of: AbbVie, Arena, Biogen, Bristol Myers Squibb, Dermavant, Eli Lilly, Janssen, Novartis, Pfizer Sun Pharma, and UCB Pharma, lain McInnes Consultant of: AbbVie, Bristol Myers Squibb, Celgene, Eli Lilly, Gilead, Janssen, Novartis, Pfizer, and UCB Pharma, Grant research support from: Bristol Myers Squibb, Celgene, Eli Lilly, Janssen, and UCB Pharma, Atul Deodhar Speakers bureau: AbbVie, Amgen, Eli Lilly, Janssen, Novartis Pfizer, UCB Pharma, Consultant of: AbbVie, Amgen, Boehringer Ingelheim, Bristol Myers Squibb, Celgene, Eli Lilly, Galapagos, GlaxoSmithKline, Janssen, Novartis Pfizer, UCB Pharma, Grant/research support from: AbbVie, Eli Lilly, GlaxoSmithKline, Novartis, Pfizer, UCB Pharma.

DOI: 10.1136/annrheumdis-2021-eular.437

\section{AB0527 CORRELATIONS BETWEEN REDUCTIONS IN FATIGUE SEVERITY AND IMPROVEMENTS IN PHYSICAL FUNCTION AND CLINICAL RESPONSE IN PATIENTS WITH PSORIATIC ARTHRITIS: RESULTS FROM THE PHASE 3 DISCOVER PROGRAM}

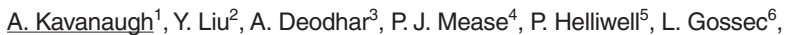
A. Kollmeier ${ }^{2}$, E. C. Hsia ${ }^{2,7}$, M. Shawi ${ }^{8}$, C. Han $^{2}$, P. Rahman ${ }^{9}{ }^{1}$ University of California San Diego, Center for Innovative Therapy, San Diego, United States of America; ${ }^{2}$ Janssen Research \& Development, LLC, Immunology, Spring House, United States of America; ${ }^{3}$ Oregon Health \& Science University, Division of Arthritis and Rheumatic Diseases, Portland, United States of America; ${ }^{4}$ Swedish Medical Center/Providence St. Joseph Health and University of Washington School of Medicine, Rheumatology Research, Seattle, United States of America; ${ }^{5}$ University of Leeds, Leeds Institute of Rheumatic and Musculoskeletal Medicine, Leeds, United Kingdom; ${ }^{6}$ Sorbonne Université, Hôpital Pitié-Salpétrière, Institut Pierre Louis d'Epidémiologie et de Santé Publique, Prof of Rheumatology, Paris, France; ${ }^{7}$ University of Pennsylvania School of Medicine, Rheumatology, Philadelphia, United States of America; ${ }^{8} \mathrm{Janssen}$ Global Services, LLC, Immunology, Horsham, United States of America; ${ }^{9}$ Memorial University of Newfoundland, Craig L Dobbin Genetics Research Centre, St. John's, Canada

Background: In patients (pts) with psoriatic arthritis ( $P s A)$, fatigue is a major driver of perceived impact of disease and has been identified as an important domain to be assessed in clinical trials. ${ }^{1,2}$ The association between fatigue and other PsA domains (eg, physical function) or clinical response is not well understood

Objectives: Fatigue was measured with the Functional Assessment of Chronic IIIness Therapy (FACIT)-Fatigue questionnaire in the pivotal DISCOVER-1 and DISCOVER-2 Phase 3 studies of guselkumab (GUS) vs placebo (PBO). This post hoc analysis explores the correlation between FACIT-Fatigue and physical function and clinical response in the DISCOVER program.

Methods: This analysis used pooled data from pts $(\mathrm{N}=1120)$ treated with GUS or PBO. In DISCOVER-1 and DISCOVER-2, 381 pts with active PsA (swollen joint count $[\mathrm{SJC}] \geq 3$, tender joint count $[T J C] \geq 3$, C-reactive protein $[\mathrm{CRP}]$ $\geq 0.3 \mathrm{mg} / \mathrm{dL}$ ) and 739 pts with active PsA (SJC $\geq 5, T J C \geq 5$, CRP $\geq 0.6 \mathrm{mg} / \mathrm{dL}$ ) and inadequate response to standard therapies, respectively, were randomized 1:1:1 to GUS $100 \mathrm{mg}$ Q4W; GUS $100 \mathrm{mg}$ at W0, W4, then Q8W; or PBO. PBO pts switched to GUS $100 \mathrm{mg} \mathrm{Q4W} \mathrm{at} \mathrm{W24.} \mathrm{The} \mathrm{FACIT-Fatigue} \mathrm{questionnaire}$ has 13 items that assess self-reported fatigue/tiredness over the last 7 days. Items are scored from 0 (very much fatigued) to 4 (not at all fatigued). FACIT-Fatigue response was defined as an increase of $\geq 4$ points from baseline. Physical function was evaluated with the Health Assessment Questionnaire-Disability Index (HAQ-DI). HAQ-DI response was defined as a decrease of $\geq 0.35$ points from baseline. Clinical response was defined as achievement of $\geq 20 \%$ 
improvement in the American College of Rheumatology (ACR 20) criteria. Relationships between FACIT-Fatigue and HAQ-DI at W8/16/24 were assessed by Pearson correlation coefficients. Mean changes in HAQ-DI scores at W8/16/24 were summarized in FACIT-Fatigue responders and nonresponders. A logistic regression model was applied to estimate odds ratios (ORs) for achievement of HAQ-DI and ACR 20 response by FACIT-Fatigue response status at each visit. A multiple linear regression model was used to evaluate the association between FACIT-Fatigue and HAQ-DI at W24 after adjusting for SJC, TJC, CRP, and pt assessment of pain.

Results: FACIT-Fatigue and HAQ-DI scores and changes from baseline were negatively correlated at W8, W16, and W24 (Table 1). Mean changes in HAQ-DI were $-0.31,-0.43$, and -0.48 at $\mathrm{W} 8, \mathrm{~W} 16$, and $\mathrm{W} 24$, respectively, in FACIT-Fatigue responders and $-0.06,-0.07$, and -0.09 , respectively, in FACIT-Fatigue nonresponders. FACIT-Fatigue responders were significantly more likely than nonresponders to achieve HAQ-DI and ACR 20 response (OR $[95 \% \mathrm{Cl}]$ at $\mathrm{W} 8,2.8$ [2.2-3.7] and 2.4 [1.9-3.1]; at $\mathrm{W} 16$, 3.6 [2.8-4.7] and 2.9 [2.3-3.7]; and at W24, 4.4 [3.4-5.7] and 3.2 [2.5-4.2], respectively; Figure 1). Correlations between FACIT-Fatigue and HAQ-DI remained significant after adjusting for SJC, TJC, CRP, and pt assessment of pain

Conclusion: In pts with PsA, fatigue response is a clinically meaningful predictor of improvements in physical function and achievement of ACR 20 response, reinforcing the importance of assessing fatigue in PsA disease management.

REFERENCES:

[1] Leung YY et al. J Rheumatol. 2020;96:46-9.

[2] Gudu T et al. Joint Bone Spine. 2016;83:439-43.

Table 1. Correlation* of FACIT-Fatigue and HAQ-DI

\begin{tabular}{lcc}
\hline Visit & $\begin{array}{c}\text { HAQ-DI and FACIT } \\
\text { Fatigue Scores }\end{array}$ & $\begin{array}{c}\text { Changes From Baseline in HAQ-DI and } \\
\text { FACIT-Fatigue Scores }\end{array}$ \\
\hline W8 & $-0.61(p<0.0001)$ & $-0.42(p<0.0001)$ \\
W16 & $-0.60(p<0.0001)$ & $-0.47(p<0.0001)$ \\
W24 & $-0.62(p<0.0001)$ & $-0.50(p<0.0001)$ \\
\hline
\end{tabular}

${ }^{\star}$ Determined by Pearson correlation coefficient; $p$-values derived from hypothesis tests of correlation $\rho=0$ (ie, no correlation).

FIgure. HAQ-DI and ACR 20 Responders by FACIT-Fatigue Responder Status (Y/N)

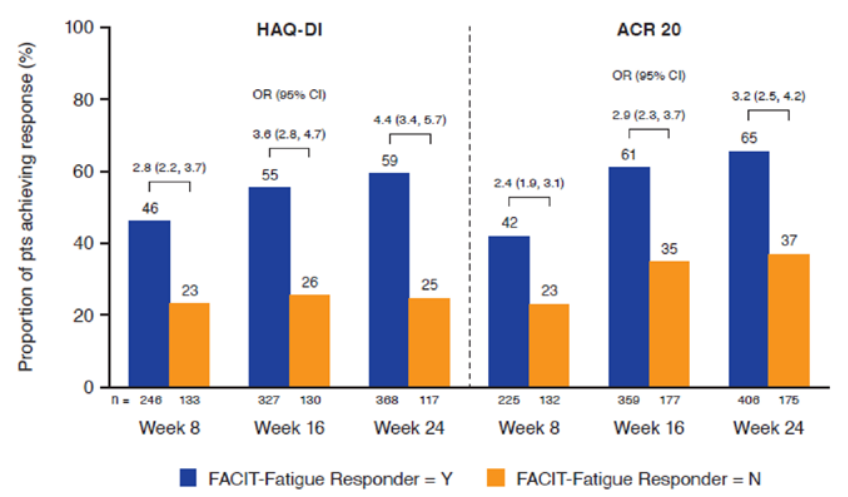

Figure 1

Disclosure of Interests: Arthur Kavanaugh Consultant of: AbbVie, Amgen, Bristol Myers Squibb, Genentech, Janssen, Eli Lilly, Merck, Novartis, Pfizer and UCB, Grant/research support from: AbbVie, Amgen, Bristol Myers Squibb, Genentech, Janssen, Eli Lilly, Merck, Novartis, Pfizer and UCB, Yan Liu Shareholder of: Johnson \& Johnson, Employee of: Janssen Research \& Development, LLC, Atul Deodhar Speakers bureau: AbbVie, Eli Lilly, Janssen, Novartis, Pfizer, UCB, Consultant of: AbbVie, Amgen, Boehringer Ingelheim, Bristol Myers Squibb, Celgene, Eli Lilly, Galapagos, GSK, Janssen, Novartis, Pfizer, UCB, Grant/research support from: AbbVie, Eli Lilly, GSK, Novartis, Pfizer, UCB, Philip J Mease Grant/research support from: AbbVie, Amgen, Bristol Myers Squibb, Eli Lilly, Galapagos, Gilead, Janssen, Novartis, Pfizer, SUN, and UCB; and personal fees from Boehringer Ingelheim and GlaxoSmithKline, Philip Helliwell Consultant of: Galapagos, Janssen, Novartis, Grant/ research support from: Abbvie, Janssen, Pfizer, Laure Gossec Consultant of: AbbVie, Amgen, Bristol Myers Squibb, Biogen, Celgene, Gilead, Janssen, Eli Lilly, Novartis, Pfizer, Samsung Bioepis, Sanofi-Aventis, UCB, Grant/ research support from: Amgen, Galapagos, Janssen, Eli Lilly, Pfizer, Sandoz, Sanofi, Alexa Kollmeier Shareholder of: Johnson \& Johnson, Employee of: Janssen Research \& Development, LLC, Elizabeth C Hsia Shareholder of: Johnson \& Johnson, Employee of: Janssen Research \& Development LLC, May Shawi Shareholder of: Johnson \& Johnson, Employee of: Janssen Global Services, LLC, Chenglong Han Shareholder of: Johnson \& Johnson, Employee of: Janssen Research \& Development, LLC, Proton Rahman Speakers bureau: AbbVie, Eli Lilly, Janssen, Novartis, Pfizer, and UCB, Consultant of: AbbVie, Amgen, Bristol Myers Squibb, Celgene, Eli Lilly, Janssen, Novartis, Pfizer, Roche, and UCB, Grant/research support from: Janssen and Novartis.

DOI: 10.1136/annrheumdis-2021-eular.475

\section{$\mathrm{AB} 0528$ \\ COMPARABLE SAFETY PROFILE OF GUSELKUMAB IN PSORIATIC ARTHRITIS AND PSORIASIS: RESULTS FROM PHASE 3 TRIALS THROUGH 1 YEAR}

A. B. Gottlieb , J. F. Merola ${ }^{2}$, A. Armstrong ${ }^{3}$, R. Langley ${ }^{4}$, M. Lebwohl ${ }^{1}$, C. E. M. Griffiths ${ }^{5}$, M. Shawi ${ }^{6}$, Y. W. Yang ${ }^{6}$, E. C. Hsia ${ }^{7,8}$, A. Kollmeier ${ }^{9}$, X. L. Xu ${ }^{9}$, M. Izutsu ${ }^{9}$, P. Ramachandran ${ }^{10}$, S. Sheng ${ }^{11}$, Y. You ${ }^{11}$, M. Miller ${ }^{10}$, C. T. Ritchlin ${ }^{12}$, I. Mclnnes ${ }^{13}$, P. Rahman ${ }^{14}$. ${ }^{1}$ Icahn Medical School/Mount Sinai, Department of Dermatology, New York, United States of America; ${ }^{2}$ Brigham and Women's Hospital, Harvard Medical School, Dermatology, Rheumatology, Immunology and Allergy, Boston, United States of America; ${ }^{3}$ Keck School of Medicine, University of Southern California, Clinical Research, Los Angeles, United States of America; ${ }^{4}$ Dalhousie University, Division of Clinical Dermatology \& Cutaneous Science, Halifax, Canada; ${ }^{5}$ The University of Manchester, Manchester Centre for Dermatology Research, Manchester, United Kingdom; ${ }^{6}$ Janssen Global Services, LLC, Immunology, Horsham, United States of America; ${ }^{7}$ University of Pennsylvania School of Medicine, Rheumatology, Philadelphia, United States of America; ${ }^{8}$ Janssen Research \& Development, LLC, Immunology, Spring House, United States of America; ${ }^{9}$ Janssen Research \& Development, LLC, Immunology, San Diego, United States of America; ${ }^{10}$ Janssen Research \& Development, LLC, Immunology, Spring House, United States of America; ${ }^{11}$ Janssen Research \& Development, LLC, Biostatistics, Spring House, United States of America; ${ }^{12}$ University of Rochester, Department of Medicine, Allergy/Immunology and Rheumatology, Rochester, United States of America; ${ }^{13}$ University of Glasgow, Institute of Infection Immunity and Inflammation, Glasgow, United Kingdom; ${ }^{14}$ Memorial University of Newfoundland, Craig L Dobbin Genetics Research Centre, St. John's, Canada

Background: DISCOVER 1\&2 (PsA) and VOYAGE 1\&2 (PsO) are Phase 3 trials of guselkumab (GUS).

Objectives: Compare safety results through up to 1yr of GUS in PsA and PsO pts.

Methods: In DISCOVER, 1120 pts with active PsA despite standard therapy were treated. Most pts were biologic-naïve; $30 \%$ in DISCOVER 1 had previous exposure to $1-2$ TNFi. Concomitant MTX (57\%), oral corticosteroids (17\%), and NSAIDs (64\%) were permitted. Pts were randomized to SC GUS $100 \mathrm{mg}$ at W0, W4, then Q8W; GUS 100mg Q4W; or PBO. At W24, PBO patients were switched to GUS 100mg Q4W. In VOYAGE, in which concomitant MTX use was prohibited, 1245 pts with moderate to severe $\mathrm{PsO}$ were treated and randomized to SC GUS $100 \mathrm{mg}$ at W0, W4, W12, then Q8W; or PBO at W0, W4, W12, with crossover to GUS at W16, W20, then Q8W. AEs and laboratory parameters, analyzed by National Cancer Institute-Common Terminology Criteria for AEs [NCl-CTCAE] toxicity grades, were summarized through the PBO-controlled periods and 1yr.

Results: Safety profiles were generally consistent across the GUS PSO and PSA clinical programs (Table 1). Time-adjusted incidence rates for numbers of AEs, serious AEs, serious infections, malignancy, MACE and AEs leading to $d / c$ were generally similar between PsO and PsA. No cases of anaphylaxis or opportunistic infections were reported. Proportions of pts with decreased neutrophil counts and elevations in hepatic transaminases were slightly higher in PsA vs PsO. These abnormalities were mostly of NCl-CTCAE Grade 1 or $2\left(<\mathrm{LLN}-1000 / \mathrm{mm}^{3}\right.$ for neutrophils; <5.0 $x$ ULN for AST/ ALT), generally transient, required no medical interventions, resolved spontaneously, and did not lead to interruption or $\mathrm{d} / \mathrm{c}$ of treatment. Through 1yr, proportions of pts with ALT/AST elevations in PsA trials were slightly higher for GUS Q4W than Q8W and in pts with vs without baseline MTX use.

Conclusion: The GUS safety profile was generally consistent in PsA and PsO GUS-treated pts through 1yr of the DISCOVER and VOYAGE trials. 